\title{
EFICÁCIA DE HERBICIDAS NO CONTROLE PÓS-EMERGÊNCIA DE CORDA-DE-VIOLA
}

\section{EFFICACY OF HERBICIDES IN THE CONTROL OF MORNING GLORY}

Gabriella Daier Oliveira Pessoa Carneiro ${ }^{\mathrm{a} *}$, Gabriel Henrique Rocha Castro ${ }^{\mathrm{a}}$, João Paulo Costa $^{\mathrm{a}}$, Maria Tereza Barbosa Silva $^{\mathrm{a}}$, Tatiane Severo Silva ${ }^{\mathrm{b}}$, Taliane Maria da Silva Teófilo ${ }^{\mathrm{b}}$, Lucas da Silva Mendes ${ }^{\mathrm{a}}$.

${ }^{a}$ Departamento de Agronomia, Centro Universitário de Patos de Minas - UNIPAM, Minas Gerais, Brasil, bepartamento de Agronomia, Universidade Federal Rural do Semi-Árido - UFERSA, Rio Grande do Norte, Brasil.

*Autor correspondente: gabrielladopc@unipam.edu.br.

\section{INFORMAÇÕES DO ARTIGO}

\section{Histórico do artigo:}

Recebido: 15 Março 2019.

Aceito: 11 Agosto 2020.

Publicado: 02 Outubro 2020.

\section{Palavras-chave/Keywords:} Manejo de plantas daninhas/ Weed management.

Tolerância/ Tolerance.

Ipomoea spp/ Ipomoea spp.

\section{Financiamento:}

Centro Universitário de Patos de Minas - UNIPAM.

Direito Autoral: Este é um artigo de acesso aberto distribuído sob os termos da Licença Creative Commons, que permite uso, distribuição e reprodução irrestritos em qualquer meio, desde que o autor e a fonte originais sejam creditados.

\section{Citação deste artigo:}

CARNEIRO, G. D. O. P.; CASTRO, G. H. R.; COSTA, J. P.; SILVA, M. T. B.; SILVA, T. S.; TEÓFILO, T. M. S.; MENDES, L. S. Eficácia de herbicidas no controle pós-emergência de cordade-viola. Revista Brasileira de Herbicidas, v. 19, n. 2. 2020.

\section{RESUMO}

O bom estabelecimento das culturas agrícolas depende de vários fatores ligados à forma de manejo das plantas daninhas. A corda-de-viola (Ipomoea sp.) é uma das plantas daninhas mais problemáticas em lavouras agrícolas no Brasil, causando redução na produção e dificultando as operações de colheita. Neste sentido, objetivou-se avaliar a eficácia de diferentes herbicidas aplicados em pós-emergência da corda-de-viola. $\mathrm{O}$ experimento foi conduzido no período de julho a setembro de 2018 em casa de vegetação. O delineamento experimental utilizado foi o de blocos casualizados (DBC), com seis tratamentos (T1 - glifosato, T2 -clorimuron-etílico, T3 - metsulfuron-metílico, T4 - carfentrazonaetílica, T5 - saflufenacil, T6 - controle sem aplicação de herbicidas), com quatro repetições. Para a determinação da eficácia de controle, foram feitas avaliações de fitointoxicação com base em uma escala visual aos 7, 14 e 21 dias após a aplicação. Neste mesmo período, foi medido o comprimento de raiz, da parte aérea e comprimento total, diâmetro de caule e matéria seca total da planta. A carfentrazona-etílica $\left(30 \mathrm{~g}\right.$ i.a. $\left.\mathrm{ha}^{-1}\right)$ e o saflufenacil (35 g i.a. $\mathrm{ha}^{-1}$ ) são eficientes no controle da corda-de-viola (Ipomoea sp.) em pósemergência por apresentar controle total desta planta daninha. O glifosato $1920 \mathrm{~g}$ e.a. ha $^{-1}$ ), clorimuron-etílico $\left(12,5 \mathrm{~g}\right.$ i.a. ha $\left.{ }^{-1}\right)$ e metsulfuron-metílico $\left(3,6 \mathrm{~g}\right.$ i.a. ha $\left.{ }^{-1}\right)$ não são recomendados para o controle de corda-de-viola (Ipomoea sp.) devido à baixa porcentagem de controle. 
G. D. O. P. CARNEIRO et al.

\section{Introdução}

A corda-de-viola (Ipomoea sp.), pertencente à família Convolvulaceae, se destaca como uma das plantas daninhas mais problemáticas em lavouras agrícolas no Brasil (PAGNONCELLI, et al., 2017). O difícil controle da cordade-viola nos cultivos agrícolas é causado por fatores que incluem sementes fisicamente dormentes que podem permanecer viáveis no solo por vários anos e hábito de crescimento entrelaçado (volúvel com hastes flexíveis) (GIANOLI, 2003). Estas características lhes permitem escalar as plantas de colheita, diminuindo a disponibilidade de luz e reduzindo a eficiência da colheita mecânica (LEON; FERRELL; SELLERS, 2016). Além de possuir períodos prolongados de emergência (PAZUCH et al., 2015; SCHUTTE et al., 2017) e tolerância a herbicidas (KUESTER; CHANG; BAUCOM, 2015).

Existem um número considerável de herbicidas registrados para o controle de corda-de-viola, como por exemplo, o glifosato, clorimuron-etílico, metsulfuronmetílico, carfentrazone-ethyl e saflufenacil (AGROFIT, 2020). O glifosato é o herbicida não seletivo mais amplamente utilizado que permite o controle de um amplo espectro de plantas daninhas em uma ampla variedade de culturas agrícolas (GONCALVES et al., 2016). Este herbicida atua inibindo a enzima 5-enolpiruvato-chiquimato3-fosfato sintase (EPSPS), impedindo a biossíntese de aminoácidos aromáticos (ALARCÓN-REVERTE et al., 2015).

O clorimuron-etílico e metsulfuron-metílico são herbicidas sistêmicos das sulfonilureias amplamente utilizados para o controle de plantas daninhas de folhas largas e gramíneas anuais em pré e pós-emergência (ACEBAL et al., 2014). Estes herbicidas atuam inibindo a enzima acetolactato sintase (ALS), bloqueando a síntese dos aminoácidos de cadeia ramificada, causando distúrbios na divisão celular (FLORES; CÓRDOVA; DÍAZ, 2009). Carfentrazone-ethyl e o saflufenacil são herbicidas inibidores da enzima protoporfirinogênio IX oxidase (PPO), precursora da clorofila (GROSSMANN et al., 2011. Estes herbicidas são aplicados isolados ou misturados com glifosato para controle de plantas daninhas dicotiledôneas por aplicações em pré e pós-emergência em uma ampla variedade de culturas agrícolas (GROSSMANN et al., 2011; KAYA-ALTOP et al., 2016).

Apesar dos herbicidas recomendados acima, alguns produtores rurais vêm relatando ineficiência de controle por algumas moléculas herbicidas, principalmente pelo glifosato. Além disso, dependendo do estágio de desenvolvimento da corda-de-viola o controle é muito difícil, destacando-se a importância de posicionar o herbicida na pós-emergência inicial (TAKANO et al., 2013). Assim, o objetivo deste estudo foi avaliar a eficácia de controle dos herbicidas glifosato, clorimuron-etílico, metsulfuron-metílico, carfentrazona-etílica e saflufenacil aplicados em condições de pós-emergência da corda-de viola (Ipomoea sp.).

\section{Material e Métodos}

O experimento foi conduzido no período de julho a setembro de 2018 em casa de vegetação do Centro Universitário de Patos de Minas, UNIPAM, na cidade de Patos de Minas, MG, Brasil, com latitude de $18^{\circ} 34^{\prime} 44^{\prime \prime} \mathrm{S}$, longitude de $46^{\circ} 31^{\prime} 05^{\prime \prime} \mathrm{W}$ e altitude de $832 \mathrm{~m}$. Segundo a classificação de Köppen e Geiger, a região apresenta um clima tropical (Aw) e temperatura média anual de $22,8^{\circ} \mathrm{C}$.

$\mathrm{O}$ experimento foi conduzido em delineamento de blocos casualizados (DBC), com seis tratamentos: T1 glifosato (Roundup Original, 1920 g e.a. ha ${ }^{-1}$ SL, Monsanto), T2 - chlorimuron-etílico (Clorimuron Master Nortox, 12,5 g i.a. ha ${ }^{-1}$, WG, Nortox), T3 - metsulfuronmetílico (Metsuram $600 \mathrm{WG}, 3,6 \mathrm{~g}$ i.a. ha ${ }^{-1} \mathrm{WG}$, Rotam), T4 - carfentrazona-etílica (Aurora, 30 g i.a. ha ${ }^{-1}$, EC, FMC), T5 - saflufenacil (Heat, 35 g i.a. ha ${ }^{-1}$, WG, Basf) e T6 controle, com quatro repetições, compreendendo um total de vinte e quatro unidades experimentais.

O solo utilizado foi coletado em uma lavoura de café da Fazenda Boa Vista, Carmo do Paranaíba, MG, Brasil. Este solo foi peneirado, autoclavado e logo após, foi colocado em vasos com capacidade de 5,5 litros. O solo é classificado como Latossolo Vermelho Distrófico e suas propriedades físicas e químicas estão apresentadas na Tabela 1. As sementes de corda-de-viola foram coletadas quando as mesmas se encontravam maduras, no mesmo local de coleta do solo. As sementes foram submetidas à secagem natural por aproximadamente doze horas. Em seguida, foram armazenadas a temperatura de $18{ }^{\circ} \mathrm{C}$, com umidade controlada de 55\%. Para garantir a máxima germinação foi realizada a quebra de dormência das sementes com ácido sulfúrico $(30 \%)$ por cinco minutos (SOUZA FILHO; DUTRA; SILVA, 1998).

Tabela 1. Caracterização física e química do solo.

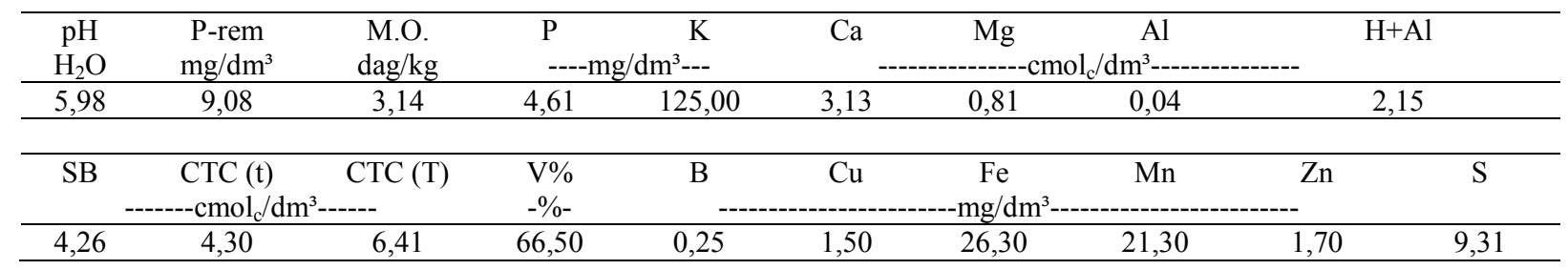


G. D. O. P. CARNEIRO et al.

Posteriormente, as sementes de corda-de-viola foram semeadas em bandeja com 200 células contendo substrato Carolina Padrão ${ }^{\circledR}$. Estas bandejas foram acondicionadas em sala com temperatura de $25^{\circ} \mathrm{C}$ e fotoperíodo de 12 horas. Quando as plântulas atingiram seu segundo par de folhas verdadeiras, foram transplantadas para os vasos em casa de vegetação, totalizando oito plantas por vaso. Após o estabelecimento das mudas nos vasos, aos 30 dias após o transplantio (acima de 6 folhas), foi feita a aplicação dos herbicidas utilizando um pulverizador costal de pressão constante à base de $\mathrm{CO}_{2}$, equipado com barra munida de duas pontas tipo jato leque XR-110.02, espaçadas a $50 \mathrm{~cm}$ entre si, sob pressão de $196 \mathrm{kPa}$. Estas condições de aplicação proporcionaram o equivalente a $200 \mathrm{~L} \mathrm{ha}^{-1} \mathrm{de}$ calda. No momento da aplicação, as condições climáticas foram constituídas por: temperatura de $23,0{ }^{\circ} \mathrm{C}$; umidade relativa de $60 \%$ e velocidade dos ventos de $4,0 \mathrm{~km} \mathrm{~h}^{-1}$.

As avaliações de controle de plantas daninhas foram realizadas aos 7, 14 e 21 dias após a aplicação (DAA). Para a determinação de controle foram feitas avaliações de fitointoxicação com base em uma escala visual adaptada da Asociación Latinoamericana de Malezas (ALAM, 1974) (Tabela 2), onde $0-40 \%$ corresponde a nenhum controle e $91-100 \%$ corresponde a controle total da espécie (Ipomoea sp.). A avaliação foi feita visualmente utilizandose como parâmetro uma escala diagramática de tecido foliar afetado pelos herbicidas.

Tabela 2. Escala utilizada para avaliação de eficácia de controle de plantas daninhas proposta pela Asociación Latinoamericana de Malezas (ALAM, 1974).

\begin{tabular}{cc}
\hline Porcentagem & Grau de controle \\
\hline $0-40$ & Nenhum \\
$41-60$ & Regular \\
$61-70$ & Suficiente \\
$71-80$ & Bom \\
$81-90$ & Muito Bom \\
$91-100$ & Excelente \\
\hline
\end{tabular}

O comprimento de planta foi mensurado utilizando uma régua graduada em centímetros. $\mathrm{O}$ diâmetro de caule foi medido acima do colo da planta, utilizando um paquímetro digital. A matéria seca total da planta foi determinada por meio da secagem das plantas, que foram acondicionadas em sacos de papel e levadas à estufa de circulação forçada de ar, onde permaneceram por um período de 48 horas a uma temperatura de $60{ }^{\circ} \mathrm{C}$. Após esse período, o material foi retirado e pesado em balança de precisão.

Os dados obtidos foram submetidos à análise de variância e suas médias comparadas pelo teste de Tukey ( $\mathrm{p} \leq 0,05)$ com o auxílio do software SISVAR, versão 5.6 (FERREIRA, 2011).

\section{Resultados e Discussão}

Os herbicidas carfentrazona-etílica e saflufenacil proporcionaram alta porcentagem de controle da corda-deviola aos 7 DAA (acima de 94,00\%) quando comparado aos demais herbicidas (Tabela 3). Carfentrazona-etílica e saflufenacil também foram os herbicidas com maior nível de controle aos 15 DAA $(98,00$ e $100,00 \%$, respectivamente) e aos 21 DAA (100,00\% para ambos os herbicidas). Metsulfuron-metílico, clorimuron-metílico e glifosato não apresentaram controle satisfatório em nenhuma das épocas de avaliação, com porcentagem de controle aos 21 DAA de 53,$50 ; 26,50$ e $25,50 \%$, respectivamente (Tabela 3 ).

Tabela 3. Porcentagem de controle de corda-de-viola avaliada aos 7, 14 e 21 DAA.

\begin{tabular}{lccc}
\hline \multirow{2}{*}{ Tratamento } & \multicolumn{3}{c}{ Controle (\%) } \\
\cline { 2 - 4 } & $\mathbf{7 ~ D A A}^{\mathbf{1}}$ & 15 DAA & 21 DAA \\
\hline Glifosato & $18,50 \mathrm{~b}$ & $22,75 \mathrm{~b}$ & $25,50 \mathrm{c}$ \\
Clorimuron-etílico & $14,75 \mathrm{~b}$ & $20,25 \mathrm{~b}$ & $26,50 \mathrm{c}$ \\
Metsulfuron-metílico & $16,50 \mathrm{~b}$ & $21,25 \mathrm{~b}$ & $53,50 \mathrm{~b}$ \\
Carfentrazona-etílica & $95,25 \mathrm{a}$ & $98,00 \mathrm{a}$ & $100,00 \mathrm{a}$ \\
saflufenacil & $94,50 \mathrm{a}$ & $100,00 \mathrm{a}$ & $100,00 \mathrm{a}$ \\
Controle & $00,00 \mathrm{c}$ & $00,00 \mathrm{c}$ & $00,00 \mathrm{~d}$ \\
\hline CV $(\%)$ & 7,00 & 4,04 & 3,11 \\
\hline
\end{tabular}

Médias seguidas de mesma letra na coluna não diferem a 5\% de probabilidade pelo teste de Tukey.

Constantin et. al. (2011) também observaram um controle de Ipomoea grandifolia no estádio de 2 a 8 folhas acima de $80 \%$ aos 3 dias após a aplicação de saflufenacil (35 $\mathrm{g} \mathrm{ha}^{-1}+$ Dash a $0,5 \% \mathrm{v} / \mathrm{v}$ ), enquanto que para carfentrazona-etílica $\left(60 \mathrm{~mL} \mathrm{ha}^{-1}+\right.$ Assist a $\left.0,5 \% \mathrm{v} / \mathrm{v}\right)$ o controle esteve em torno de $73 \%$, contudo aos 7 dias após a aplicação ambos os herbicidas apresentaram 95\% de controle, mostrando a sua eficácia e confirmando os dados obtidos nesse trabalho. Christoffoleti et al. (2006) também observaram a eficácia da carfentrazona-etílica 
G. D. O. P. CARNEIRO et al.

(50 g p.c. ha $\left.^{-1}\right)$ para controlar (100\%) diferentes espécies de cordas-de-viola (Ipomoea nil (L.) Roth. e Ipomoea grandifolia (Damm.)).

O saflufenacil também proporciona excelente controle de cordas-de-viola com 2 a 8 pares de folhas na dose de 35 g i.a. ha ${ }^{-1}$ (FOLONI, 2009; CARVALHO; QUEIROZ; TOLEDO, 2011; GROSSMANN et al. 2011). Os herbicidas carfentrazona-etílica e saflufenacil pertencem ao mecanismo de inibição da PROTOX, são moléculas absorvidas pelas folhas e raízes e proporcionam controle rápido em condições de alta temperatura e incidência solar (GROSSMANN et al. 2011; AGOSTINETO et al., 2016). Além disso, estes herbicidas da PROTOX podem ser recomendados em mistura ao glifosato, ao qual essa planta daninha é tolerante (Tabela 3), pois estes apresentam efeito sinérgico (AGOSTINETO et al., 2016).

Com relação ao glifosato, outros trabalhos também relataram a ineficiência de controle em doses de até $1920 \mathrm{~g}$ e.a. (RAMIRES et al., 2010; SOUZA; MARTINS; PEREIRA, 2013; AGOSTINETO et al., 2016). Esta ineficiência é causada por mecanismos de tolerância da corda-de-viola como absorção e translocação diferencial. Estes processos de absorção e translocação se sofrerem alterações afeta a quantidade de glifosato que chega ao local de ação não sendo suficiente para o controle. Outros processos que também afetam a eficiência é o mecanismo de metabolização do glifosato em outras substâncias, como compostos inativos ou com menores níveis tóxicos (ácido aminometilfosfônico (AMPA), glioxalato e sarcosina) (CARVALHO et al., 2012). Além da compartimentalização com a retenção das moléculas nos vacúolos (GALON et al., 2013). Ribeiro et al. (2015) constataram que a tolerância da Ipomoea lacunosa L. ao glifosato é principalmente pela translocação diferencial.

O comprimento de raiz, parte aérea e comprimento total foi menor em todos os tratamentos testados quando comparados ao controle. Entretanto, a carfentrazona-etílica e o saflufenacil causaram a morte das plantas, impossibilitando que essas variáveis fossem mensuradas (Tabela 4), o que evidencia a eficiência de controle.

Tabela 4. Comprimento de raiz, parte aérea e total de Corda-de-viola sob aplicação de diferentes moléculas de herbicidas.

\begin{tabular}{lccc}
\hline \multirow{2}{*}{ Tratamento } & & Comprimento (cm) & Total \\
\cline { 2 - 4 } & Raiz & Parte aérea & $50,72 \mathrm{~b}$ \\
\hline Glifosato & $24,57 \mathrm{c}$ & $26,15 \mathrm{~b}$ & $36,45 \mathrm{~d}$ \\
Clorimuron-etílico & $22,51 \mathrm{~d}$ & $13,94 \mathrm{c}$ & $40,95 \mathrm{c}$ \\
Metsulfuron-metílico & $28,25 \mathrm{~b}$ & $12,70 \mathrm{c}$ & $00,00 \mathrm{e}$ \\
Carfentrazona-etílica & $00,00 \mathrm{e}$ & $00,00 \mathrm{~d}$ & $00,00 \mathrm{e}$ \\
Saflufenacil & $00,00 \mathrm{e}$ & $00,00 \mathrm{~d}$ & $65,22 \mathrm{a}$ \\
Controle & $30,74 \mathrm{a}$ & $34,48 \mathrm{a}$ & 4,60 \\
\hline CV $(\%)$ & 4,21 & 7,99 & \\
\hline
\end{tabular}

Médias seguidas de mesma letra na coluna não diferem a 5\% de probabilidade pelo teste de Tukey.

Os herbicidas clorimuron-etílico, metsulfuronmetílico e glifosato reduziram o comprimento total da corda -de-viola em 44,11, 37,21 e 22,23\%, respectivamente, quando comparado ao controle. Lacerda e Victoria Filho (2004), trabalhando com a molécula de glifosato, observaram resultados divergentes dos encontrados no presente trabalho, em que em uma concentração de 1440 g e.a. ha ${ }^{-1}$, obtiveram uma redução do crescimento da corda-de-viola (Ipomoea grandifolia) próximo de 70\%.

A carfentrazona-etílica e o saflufenacil causaram total redução do diâmetro de caule e matéria seca das plantas de corda-de-viola, mais uma vez comprovando a eficiência de controle. Os herbicidas chlorimuron-etílico e glifosato reduziram o diâmetro do caule da corda-de-viola em $11,00 \%$ e o metsulfuron-metílico reduziu 3\%, quando comparado ao controle. A matéria seca foi reduzida em $36,00,15,00$ e $14,00 \%$ aos 21 DAA para os herbicidas clorimuron-etílico, metsulfuron-metílico e glifosato, respectivamente (Tabela 5). Estes resultados confirmam as baixas porcentagens de controle da corda-de-viola observadas para estes herbicidas.

Tabela 5. Diâmetro de caule e matéria seca de Corda-de-viola sob aplicação de diferentes moléculas de herbicidas.

\begin{tabular}{lcc}
\hline Tratamento & Diâmetro do caule (mm) & Matéria seca (g) \\
\hline Glifosato & $2,09 \mathrm{ab}$ & $2,39 \mathrm{~b}$ \\
Clorimuron-etílico & $2,09 \mathrm{ab}$ & $2,36 \mathrm{~b}$ \\
Metsulfuron-metílico & $1,92 \mathrm{~b}$ & $1,79 \mathrm{c}$ \\
Carfentrazona-etílica & $0,00 \mathrm{c}$ & $0,00 \mathrm{~d}$ \\
Saflufenacil & $0,00 \mathrm{c}$ & $0,00 \mathrm{~d}$ \\
Controle & $2,17 \mathrm{a}$ & $2,80 \mathrm{a}$ \\
\hline CV $(\%)$ & 6,80 & 8,56 \\
\hline
\end{tabular}

Médias seguidas de mesma letra na coluna não diferem a 5\% de probabilidade pelo teste de Tukey. 
G. D. O. P. CARNEIRO et al.

\section{Conclusões}

Carfentrazona-etílica (30 g i.a. ha $\left.{ }^{-1}\right)$ e o saflufenacil (35 g i.a. ha ${ }^{-1}$ ) são eficientes no controle da corda-de-viola (Ipomoea sp.) em pós-emergência por apresentar controle total desta planta daninha.

O glifosato $\left(1920 \mathrm{~g}\right.$ e.a. ha $\left.{ }^{-1}\right)$, clorimuron-etílico $\left(12,5 \mathrm{~g}\right.$ i.a. ha $\left.{ }^{-1}\right)$ e metsulfuron-metílico $\left(3,6 \mathrm{~g}\right.$ i.a. ha $\left.{ }^{-1}\right)$ não são recomendados para o controle de corda-de-viola (Ipomoea $\mathrm{sp}$.) devido à baixa porcentagem de controle.

\section{Referências}

Acebal, C. et al. Application of a fully integrated photodegradation-detection flow-batch analysis system with an on-line preconcentration step for the determination of metsulfuron methyl in water samples. Talanta, v. 129, p. 233-240, 2014.

Agostineto, Mauricio Crestani et al. Sinergismo de misturas de glyphosate e herbicidas inibidores da PROTOX no controle de corda-de-viola. Revista de Ciências Agroveterinárias, v. 15, n. 1, p. 8-15, 2016.

AGROFIT. Sistema de Agrotóxicos Fitossanitários. Disponível em: <http://agrofit.agricultura.gov.br/ agrofit_cons/principal_agrofit_cons $>$. Acesso em: 25 abr. 2020.

ALAM - Asociación Latinoamericana de Malezas. Recomendaciones sobre unificación de los sistemas de evaluación en ensayos de control de malezas. Alam, Bogotá, v. 1, n. 1, p. 35-38, 1974.

Alarcón-Reverte, R. et al. Concerted action of target-site mutations and high EPSPS activity in glyphosate-resistant junglerice (Echinochloa colona) from California. Pest management science, v. 71, n. 7, p. 996-1007, 2015.

Carvalho, F. T.; Queiroz, J. R. G.; Toledo, R. E. B. Eficácia do herbicida amicarbazone no controle de cordas-de-viola na cultura da cana-de-açúcar (Saccharum spp.). Revista Brasileira Herbicidas, v. 10, n. 3, p. 183-189, 2011.

Carvalho, L. B et al. Pool of resistance mechanisms to glyphosate in Digitaria insularis. Journal of agricultural and food chemistry, v. 60, n. 2, p. 615-622, 2012.

Christoffoleti, P. J.; Borges, A.; Nicolai, M.; Carvalho, S. J. P.; López-Ovejero, R. F.; Monquero, P. A. Carfentrazoneethyl aplicado em pós-emergência para o controle de Ipomea spp. e Commelina benghalensis na cultura da cana-deaçúcar. Planta Daninha, v. 24, n. 1, p. 83-90, 2006.

Constantin, J.; Biffe, D. F.; Rios, F. A.; Júnior, R. S. O.; Fhanchini, L. H. M.; Raimondi, M. A.; Gheno, E. A.; Cruz, R. F. G.; Martini, P. E. Desempenho de Heat aplicado em dessecação antecedendo a semeadura da cultura do algodoeiro para controle de corda-de-viola, trapoeraba e leiteiro. In: Embrapa Algodão-Artigo em anais de congresso (ALICE). CONGRESSO BRASILEIRO DE ALGODÃO, 8.; COTTON EXPO, 1., 2011, São Paulo. Evolução da cadeia para construção de um setor forte: Anais. Campina Grande, PB: Embrapa Algodão, 2011., 2011.

Ferreira, D. F. Sisvar: a computer statistical analysis system. Ciência e Agrotecnologia, v. 35, n. 6, p. 1039-1042, 2011.

Flores, J. L; Córdova, M. L. F.; Díaz, A. M. Flow-through optosensing device implemented with photochemicallyinduced fluorescence for the rapid and simple screening of metsulfuron methyl in environmental waters. Journal of Environmental Monitoring, v. 11, n. 5, p. 1080-1085, 2009.

Foloni, L. L. Eficiência e seletividade da mistura de glifosate + carfentrazone-ethyl, em pós-emergência na cultura de café novo. In: CONGRESSO BRASILEIRO DE PESQUISAS CAFEEIRAS, 26, 2000. Marília. Resumos... Marília: MA/PROCAFÉ, p. 197, 2000.

Galon, L. et al. Glyphosate translocation in herbicide tolerant plants. Planta Daninha, Viçosa, v. 31, n. 1, p. 193201, 2013.

Gianoli, E. Phenotypic responses of the twining vine Ipomoea purpurea (Convolvulaceae) to physical support availability in sun and shade. Plant Ecology, v. 165, n. 1, p. 21-26, 2003.

Goncalves, C. G et al. Selectivity of saflufenacil applied singly and in combination with glyphosate on coffee and citrus crops. Revista Caatinga, v. 29, n. 1, p. 45-53, 2016.

Grossmann, K. et al. Saflufenacil (Kixor ${ }^{\mathrm{TM}}$ ): biokinetic properties and mechanism of selectivity of a new protoporphyrinogen IX oxidase inhibiting herbicide. Weed Science, v. 59, n. 3, p. 290-298, 2011.

Kaya-Altop, E. et al. Long-term perennial weed control strategies: economic analyses and yield effect in hazelnut (Corylus avellana). Crop Protection, v. 80, p. 7-14, 2016.

Kuester, A.; Chang, S. M.; Baucom, R. S. The geographic mosaic of herbicide resistance evolution in the common morning glory, Ipomoea purpurea: Evidence for resistance hotspots and low genetic differentiation across the landscape. Evolutionary applications, v. 8, n. 8, p. 821$833,2015$.

Lacerda, A. L. S.; Victoria Filho, R. Curvas dose-resposta em espécies de plantas daninhas com o uso do herbicida glyphosate. Bragantia, v. 63, n. 1, p.7 3-79, 2004.

Leon, R. G.; Ferrell, J. A.; Sellers, B. A. Seed production and control of sicklepod (Senna obtusifolia) and pitted morningglory (Ipomoea lacunosa) with 2, 4-D, dicamba, 
and glyphosate combinations. Weed Technology, v. 30, n. 1, p. 76-84, 2016.

Pagnoncelli, F. D. B.; Trezzi, M. M.; Brum, B.; Vidal, R. A.; Portes, Á. F.; Scalcon, E. L.; Machado, A. Morning glory species interference on the development and yield of soybeans. Bragantia, v. 76, n. 4, p. 470-479, 2017.

Pazuch, D.; Trezzi, M. M.; Diesel, F.; Barancelli, M. V. J.; Batistel, S. C.; Pasini, R. Superação de dormência em sementes de três espécies de Ipomoea. Ciência Rural. Santa Maria, v. 45, n. 2, p. 192-199, 2015

Ramires, A. C. et al. Controle de Euphorbia heterophylla e Ipomoea grandifolia com a utilização de glyphosate isolado ou em associação com latifolicidas. Planta daninha, v. 28, n. 3, p. 621-629, 2010.

Ribeiro, D. N. et al. Possible glyphosate tolerance mechanism in pitted morningglory (Ipomoea lacunosa L.). Journal of agricultural and food chemistry, v. 63, n. 6, p. 1689-1697, 2015.

Schutte, B. J. et al. Measuring interference from midseason tall morningglory (Ipomoea purpurea) to develop a model for teaching weed seedbank effects on chile pepper. Weed Technology, v. 31, n. 1, p. 155-164, 2017.

Souza Filho, A. P. S.; Dutra, S.; Silva, M. A. M. M. Métodos de superação da dormência de sementes de plantas daninhas de pastagens cultivadas da Amazônia. Planta Daninha, v. 16, n. 1, p. 3-11, 1998.

Souza, G. S. F.; Martins, D.; Pereira, M. R. R. Efeito da chuva na eficiência de herbicidas aplicados em pósemergência sobre corda-de-viola. Planta Daninha, v. 31, n. 1, p. 175-184, 2013.

Takano, H. K. et al. Efeito da adição do 2, 4-D ao glyphosate para o controle de espécies de plantas daninhas de difícil controle. Revista Brasileira de Herbicidas, v. 12, n. 1, p. 1-13, 2013. 